\title{
Combined electricity pricing model taking into account the "green tariff" and traditional factors
}

\author{
Yuliia Halynska ${ }^{1, *}$, Tetiana Bondar $^{1}$ \\ ${ }^{1}$ Department of Management, Sumy State University, 40000 Rimskogo-Korsakova Str.Sumy, Ukraine
}

\begin{abstract}
The article proposes a new optimization model of systemic relationships and effects in the formation of a pricing policy for electricity from combined sources of electricity, taking into account indicators of anthropogenic impact and non-renewable resources, socio-environmental and economic interests of society in the distribution of rental income. The model in the end result provides for the formation of a combined model of tariff setting in the energy sector, according to which electricity tariffs for the end user of the corresponding region will combine both market prices for energy generated from alternative sources and prices for energy generated from traditional sources. The authors improved the scientific and methodological approach to identify, formalize and quantify the multiplier effects that arise as a result of a combination of non-renewable and renewable sources of electricity. Also, the article improves the scientific and methodological approach to assessing the benefits of combining different sources of electricity and their advantages when forming a pricing policy within a single energy strategy.
\end{abstract}

\section{Introduction}

The need to optimize pricing mechanisms in the energy sector of Ukraine is particularly relevant given the requirements defined by the Energy Strategy of Ukraine regarding the fundamental transformation of the electricity market, the growth in the use of nontraditional renewable energy sources, and distributed generation facilities (in Ukraine, traditional energy in the overall structure of electricity production is $98 \%$, "green "- $2 \%$ ), the urgency of implementing measures to save energy, conserve natural resources.

The existing mechanism for pricing electricity from non-renewable sources is imperfect, because it does not take into account the principle of social justice: the anthropogenic impact and harm to public health in the regions where TPPs are located is much greater than in the regions where they are not available; the volume of electricity consumption by certain regions of Ukraine is much less than the volume of its "dirty" production; only $5 \%$ of rental income from subsoil use in the extraction of oil, natural gas and gas condensate are allocated to local and district budgets (which can be used to compensate for electricity tariffs for the population of this region), and $95 \%$ to the State budget. Regarding alternative energy, the regulated prices for green electricity do not completely cover the cost of its production (state expenditures on this energy sector reached almost nine billion Euros), as well as damage to the environment and public health, solar and wind farms are set in the regions regardless of the need for this, but rather based on natural and climatic capabilities, while a high

\footnotetext{
*Corresponding author: galinskaja.julia@gmail.com
}

concentration of tens of megawatts in a certain area leads to an imbalance in the overall energy "pot".

Considering that the main world trends in the development of energy is to deepen the integration of energy systems, the article proposes to create a combined pricing model, taking into account traditional and green energy, which can be used for regional differentiation of retail electricity tariffs for end consumers, taking into account the destructive impact of energy facilities on the environment and public health in the region, as well as a fair mechanism for the redistribution of rental income.

\section{Literature review}

Given the need for the successful implementation of the Energy Strategy of Ukraine, the functioning of a new electricity market in Ukraine, the increase in green energy production, the urgency of introducing energy conservation measures, improving the economic valuation of natural resources, the issue of optimal pricing, the energy sector in Ukraine is of particular relevance and importance. An analysis of the literature showed that today the main factors in the development of the energy sector, trends in the development of energy policies in regional management have already been considered, the need to take into account the marketing concept in the study of the energy sector in order to identify and take into account the interests of all stakeholders is justified [1,2]. The influence of the implementation of reforms in the functioning of the 
electricity market on the activities of the subsidiary of JV "NEC Ukrenergo" was studied, and the consequences of its reorganization and the risks associated with this process were evaluated [3]. Price factors were also investigated in the fuel and energy complex and summarized the approaches of different countries in setting tariffs for energy resources [4]. In [1, 2], types of business models in the energy sector were systematized and investigated, the need to adapt the financial issues associated with these models to the renewable energy market was discovered, the structure of the electricity market was proposed, which allows efficient use of available resources, and also take into account parameters of renewable energy in the process of public administration.

The paper [3] proposed a dynamic pricing mechanism that encourages consumers to adaptive consumption, in order to compensate for the constant change in demand in the energy market.

In the article [4], the authors investigated the issue of forming a moderate and reasonable price for end consumers of electricity in competitive conditions. Price is considered as one of the basic factors in the development of competition in the energy market. The authors also examine the procedure for the formation of reasonable network tariffs, that is, the retail price of energy, which is relevant in the context of the development of the electricity market. The types of business models in the energy sector are analyzed and generalized, the need for adapting the financial principles of these models to the variable market of renewable energy is discovered, the structure of the electricity market is proposed, which makes it possible to efficiently use available resources, make effective investments in new resources, and also take into account the features of renewable energy sources at the level of government $[5,6]$. In order to compensate for the variability of demand in the energy market, a dynamic pricing mechanism has been proposed that stimulates consumers [7]. The issue of formation of reasonable prices for final consumers of electricity in competitive conditions was investigated and mathematical principles of modeling in the energy sector were proposed taking into account global trends in modeling of energy processes $[8,9,10]$. In particular, in article [9], static and dynamic models for calculating prices from various alternative sources of electricity are presented taking into account the economic indicators of a closed macroeconomic system, and transient processes are studied taking into account maintaining the balance of the macroeconomic system. The trends in the development of mathematical systems of energy models are also generalized, and a mathematical model of the competitive equilibrium of the electricity market as a system of non-linear programming problems is considered [10]. The authors of the article investigated the issue of the formation and equitable distribution of rents in the extractive industry and the environmental impact of the operation of the extractive industry and the energy sector of Ukraine.

The analysis of the literature shows that the proposed topic is well researched, but that the authors of the article propose to consider the subsequent development in applied research of the mechanism of an effective combination of rent-seeking and policy, Aimed at stimulating the development of «green» energy, formalizing the process of pricing, in the energy sector on the basis of restored and non-renewable sources, Development of the organizational economic mechanism and optimization model of pricing in the energy sector of Ukraine, which will make it possible to take into account the introduced principles of the «green» economy in the process of equitable redistribution of natural resource rents.

The aim of the article is to develop an optimum model for the formation of regionally differentiated price systems, which includes anthropogenic pressure on human health and territories during the production of «green» and traditional electricity, as well as the equitable distribution of rents, for non-returnable sources of electricity in a single socio-economic chain.

\section{Research Methods and Results}

Today in the Ukrainian market there is a situation where consumers of electricity need to choose between "traditional" and "green" sources of production. On the one hand, an already existing, tested system with guaranteed receipt of services in the energy sector, but with a high price for their consumption, on the other hand, a new, energy-saving, environmentally friendly system. At the same time, the purchase price for green electricity is quite high, which is due to the stimulation of its production. This problem was especially urgent in the context of integration with the European Union, the formation of a single European energy market and the dominance of the scenarios of the energy system of European countries. Existing coal pricing mechanisms as the main source of electricity in Ukraine ("Costs + incentive tariff" and "Rotterdam +"), focused mainly on the indicative price, and not on the domestic price of resource extraction. At the same time, the rental component is not taken into account and is not used to minimize electricity tariffs in the regions where the resource is extracted. In the production of "green" electricity, the anthropogenic burden on the health of the population and the territory of electricity production is not taken into account, which, in turn, should influence the minimization of tariffs for the final consumer of these territories. Therefore, the implementation of a systematic approach to combining traditional energy, taking into account rental policies aimed at saving natural resources, the socio-economic development of the regions and green energy, will help minimize electricity prices through an optimal ratio of the used resource and obtain a multiplier effect. Redistributed rental income at the regional level will be through a system of funds that will operate as mixed (development funds and savings funds) with a high level of selfgovernment. Structurally, they will include funds to recreate the natural landscape complex of the region and compensate for the negative health effects of the 
population from the production of electricity from both traditional and alternative sources of electricity [15].

The main idea of this article is to build an author's optimization model that takes into account systemic relationships when pricing electricity from nonrenewable and renewable sources of electricity. A balanced combination of prices from the "traditional" and "green" energy policies in the country will allow us to detect, formalize and quantify the most efficient and fastest mechanisms for generating electricity at optimal prices, taking into account rental income from "traditional" sources of electricity and indicators of human impact on the environment public health from the use of combined ("traditional" and "green") sources of electricity production. The basic determinant that shaped the idea of the project is the complexity of the problem being studied (subjects and objects involved in the pricing process for "traditional" sources of electricity and prices for "green" energy connected into a single nationwide chain, which, when Ukraine is integrated into a single European energy market that is stipulated by the "Energy Strategy of Ukraine until 2035" should be competitive and implement a policy of preserving natural resources for future generations), therefore, the project proposes comprehensive optimization economic and mathematical solutions to solve it.

The main hypothesis is that the formation of a system of differentiated prices in the form of a "pricing map" for electricity for different regions of Ukraine will help minimize electricity tariffs for the end user. At the same time, the factors of anthropogenic impact on the environment and public health in the territory of electricity production and, in addition, for the "traditional" energy will be a fair redistribution of natural resource rent from non-renewable sources to a significant factor in minimizing prices for both traditional and green energy electricity (gas, coal).

\subsection{Methods}

The methodological basis of the study is the fundamental principles of economic theory, essential theory, state regulation of the economy, optimization, economic forecasting, scenario and rental approaches. The novelty of the research approach is the development of methodological tools for modeling and optimizing the processes of electricity pricing from renewable and nonrenewable sources, between which there are complex convergent connections, which are manifested in the interchangeability of different sources of electricity and synergetic effects, the formalization and accounting of which can be carried out with using the traditional mathematical apparatus of clear logic. Different methods were used to solve the tasks posed in the article: a systematic structural analysis (when substantiating price parameters according to existing electricity schemes ("Costs + incentive tariff" and "Rotterdam +"); comparative analysis (when summarizing world and domestic experience in electricity pricing, when systematizing approaches to assessing risks and threats when combined into a single chain of "traditional" and "green" energy for the national economy), economic and mathematical modeling (when constructing an optimization model for the formation of a pricing policy for electricity from renewable and non-renewable resources, taking into account socio-environmental and economic interests in the distribution of rental income).

Based on retrospective analysis of energy efficiency pricing and resource policies (in terms of electricity tariff formation), algorithms for the implementation of projects aimed at the introduction of an integrated model in the energy sector, the distribution of natural resources, a combined pricing model for the energy sector has been developed for the socio-economic development of the regions and for the operation of funds for the redistribution of natural resource rents at the regional level. For the formation of a systematic model of pricing in the energy sector, the paper proposes the "Value Chain of the Production and Use of Energy" (Fig. 1)

The formalized form of the pricing model in the energy sector: The objective function of the model to satisfy the interests of all stakeholders in the energy sector is:

$$
\begin{aligned}
& Y(C, P, \operatorname{Pr}, I, E, E f, B, P U B L, P P, \text { Inst })= \\
& =f\left(X_{c}, X_{p}, X_{p r}, X_{i}, X_{e}, X_{e f}, X_{b}, X_{p u b l}, X_{p p}, X_{\text {inst }}\right) \rightarrow \max
\end{aligned}
$$

where $X_{c}$ - consumer's economic benefit; $X_{p}$ - working conditions and economic benefits of energy sector personnel; $X_{p r}$ - profit of electricity suppliers; $X_{i}-$ extractive industry profits; $X_{e}$ - profits of other energy sector enterprises; $X_{e f}$ - energy efficiency and sustainable living; $X_{b}$ - increase in budget revenues, environmental safety; $X_{\text {publ }}$ - providing reliable public information on the level of environmental safety and the degree of anthropogenic pressure in the regions; $X_{p p}-$ redistribution of part of rental income in the region in the system "state - region - enterprise" [15]; $X_{\text {inst }}$ - benefits from the reallocation of cash flows in energy use; $C, P$, Pr, I, E, Ef, B, PUBL, PP, INST - interests of relevant stakeholder groups.

$$
X^{*}=\left(\begin{array}{l}
X_{c}^{*}, X_{p}^{*}, X_{p r}^{*}, X_{i}^{*}, X_{e}^{*}, X_{e f}^{*}, \\
X_{b}^{*}, X_{p u b l}^{*}, X_{p p}^{*}, X_{i n s t}^{*}
\end{array}\right)
$$

This is the optimal solution from a number of alternatives.

The intermediate goal of the model is to minimize electricity prices for end consumers:

$$
\left(C_{e . t .}+C_{\text {transp.e }}+C_{\text {e.renew }}+M-P_{r i}\right)^{*} C_{a . l} \rightarrow \min
$$

$C_{\text {e.t. }}-$ cost of electricity generated using traditional sources; $C_{\text {transp.e }}$ - transmission and distribution costs; $\mathrm{M}$ - margin for electricity providers; $P_{r i}$ - redistributed rental income; $C_{a . l .}$ - anthropogenic load factor for a given region; $C_{\text {e.renew }}-$ cost of electricity generated using renewable sources.

The system of model restrictions is based on resource constraints, as well as on the market pricing mechanism:

$$
\begin{gathered}
C_{\text {e.t. }}+C_{\text {fuel }}+M \leq P_{\text {retail }} \\
C_{\text {transp.e }}+M \leq P_{\text {wholesale }} \\
I_{\text {a.l.actual }} \leq I_{\text {a.l.s. }}
\end{gathered}
$$




$$
C_{\text {e.renew }}+M \leq T_{g}
$$

$P_{\text {retailv }}$ - retail price of electricity;

$P_{\text {wholesale }}$ - wholesale market electricity price;

$C_{f u e l}$ - production costs of the main types of fuel that are used for electricity generation;

$I_{\text {a.l.actual }}$ - actual anthropogenic load from fuel extraction and energy generation;

$I_{\text {a.l.s }}$ - environmental standard;

$T_{g}$ - green tariff for electricity generated from renewable sources.

The value chain for obtaining and using energy is the basis for building a pricing mechanism. The pricing mechanism takes into account the receipt of energy from both non-renewable and renewable sources. Moreover, the new pricing mechanism should take into account the interests of all stakeholders in the energy sector. The electricity market includes among other participants both national and local generators, which, for example, are households that have solar panels.

\subsection{Results}

The pricing mechanism provides for the correction of electricity prices by the coefficient of anthropogenic load in a particular region, as well as the redistribution of rental income, taking into account the interests of all stakeholders. The expected result from the formation and implementation of the optimization model will be the formation of a "pricing map" for electricity for the regions of Ukraine, focused on minimizing tariffs for the final consumer, given the fair coordination of the interests of the state and society in the process of redistributing natural resource rents, ensuring the environmental safety of the regions, and their balanced socially -economic development and public health. Subsequently, on the basis of a combined model, it is possible to create a database of regions of Ukraine with the maximum use of renewable sources of electricity production and non-renewable sources, taking into account the innovative mechanism for the redistribution of rental income in the system "state - region, extraction of natural resources (gas, coal) - mining enterprise".

Additional relevant effects in the form of natural resource rent and indicators of anthropogenic impact on the health of the population and the territory of electricity production will contribute to the formation of a mechanism of differentially adjusted tariffs for each region of Ukraine.

The results of the study can be integrated as a planning tool for integrated regional programs for the modernization of electricity tariffs.

\section{Conclusion}

World forecasts show that the next 25 years, the main sources of energy supply will remain natural gas, coal, renewable energy and energy efficiency. The consumption of natural gas by 2030 will increase by approximately $20 \%$ and will remain at the same level until 2040, and taking into account the obligations of the countries of the world to implement the Paris Climate Agreement and the intensive development of low carbon and renewable energy sources, an increase in the consumption of natural gas is forecasted for this period up to $45 \%$. At the same time, global energy development trends are characterized by deepening integration of energy systems, an increase in the use of non-traditional renewable energy sources, and a distributed generation lens. However, in the general structure of electricity production in Ukraine, traditional energy is $98 \%$ and only $2 \%$ is "green".

Therefore, the development of an optimization model for pricing policy when applying an integrated approach combining traditional and green energy, taking into account the anthropogenic impact on the territory and the fair distribution of rental income from the production of non-renewable sources of electricity, is fully justified, economically justified for the national economy.

This approach promotes electricity pricing based on climatic and relief zones and regions of extraction of mineral resources with the aim of differentially adjusting electricity payments, modernizing financial regional institutions, modernizing the existing one and creating a new "electricity pricing map" in the regions of Ukraine based on the developed optimization model. The expected results of the combined model substantially deepen the scientific principles of analysis and modelling of complex transformational processes in the energy sector of Ukraine through the creation of a scientific basis and applied methodological tools for tariff formation on electric power through the introduction of an integrated optimization model, which is partly based on the creation of synergies in the allocation of natural resource rents.

The value of the expected results for domestic science also lies in the fact that local features will be taken into account in the model (of course, the resource potential of the regions, the available pricing for electricity, the extraction of energy resources in the regions, the domestic specifics of tariff setting and the like) and a mechanism of an integrated approach in combination " green "and" traditional "energy for optimal pricing of electricity for the regions of Ukraine.

The value for world science will also be the application of the dualistic objective function of the proposed model according to the principle of finding the optimum between maximizing the economic effect and reducing the environmental burden on participants in the energy market and the environment.

\section{Question for discussion}

The project results are of value to the development needs of the real sector of the economy, the country's energy system, national security, and aimed at determining electricity tariffs from the use of an integrated model. The implementation of the mechanism for the formation of a pricing policy for electricity from combined sources of electricity will contribute to the socio-economic development of the regions, the preservation of natural resources and the environment. The combination of 
green and traditional energy in a single price chain will reduce the economic burden on individual sectors and subsystems of the national economy.

The differential approach regarding tariff setting and the creation of a "pricing map" for electricity for different regions of Ukraine will take into account rental income from non-renewable sources of electricity and take into account the destructive impact of energy facilities on the environment and public health in the region (both from "green" and "traditional" power engineer) which will be partially aimed at minimizing electricity tariffs for the end consumer. The rental income at the regional level will be redistributed through a system of decentralizing funds, the funds of which are used by regional authorities to recreate (the purpose is to recreate the region's natural landscape complex); compensation (purpose - to overcome the negative social and environmental consequences of the functioning of the fuel and energy complex); and reservation (purpose reservation for future generations in order to convert the proceeds from non-recoverable assets into a more diversified portfolio of assets).

\section{References}

1. O. Strishenets, Economic Journal of the Lesia Ukrainka East European National University. No.1, pp. 73-79 (2016) URL: http://www.irbisnbuv.gov.ua/cgi-bin/irbis_nbuv/cgiirbis_64.exe?I21 DBN=LINK\&P21DBN=UJRN\&Z21ID=\&S21REF $=10 \& S 21 C N R=20 \& S 21 \mathrm{STN}=1 \&$ S21FMT $=$ ASP $\mathrm{m}$ eta\&C21COM=S\&2_S21P03=FILA=\&2_S21STR= echcenu_2016_1_15

2. L.M. Titarenko, Economy and society. Vol. 11 (2017) URL: http://www.economyandsociety.in.ua/journal/11_uk r/52.pdf

3. Y.D. Kostin, V.S. Telegin, Bulletin of Economic Science of Ukraine. No.1 (2017) URL: http://dspace.nbuv.gov.ua/bitstream/handle/1234567 89/123070/13-Kostin.pdf?sequence=1

4. Yu.V. Shovkaluk, A young scientist. No.2 (29) (2016) URL: http://molodyvcheny.in.ua/files/journal/2016/2/33.p df

5. S. Bryant, C. Wrigley, K. Straker, Journal of Cleaner Production. 195. pp. 1032-1046 (2018) URL:

https://www.researchgate.net/publication/32544536 0_The typologies_of_power_Energy_utility_busine ss_models_in_an_increasingly_renewable_sector

6. P. Cramton, Oxford Review of Economic Policy. Vol. $33 \quad$ (4) (2017) URL: https://academic.oup.com/oxrep/article/33/4/589/45 $\underline{87939}$

7. John N. Tsitsiklis, Yunjian Xu, European Journal of Operational Research. 14 (2015) URL: http://www.mit.edu/ jnt/Papers/J154-15-Yunjianelectricity-EJOR-fin.pdf

8. S. Pront-van Bommel, A Journal of Consumer Policy. Vol. 39 (2) (2016) URL:
https://link.springer.com/content/pdf/10.1007\%2Fs1 0603-015-9300-X.pdf

9. V.Ya. Zhuykov, Yu. S. Yamnenko, I.Yu. Boyko, L.E. Klepach, Bulletin of ZhSTU. Ser. Technical sciences. No.3(78) (2016) URL: http://www.irbisnbuv.gov.ua/cgi-

bin/irbis_nbuv/cgiirbis_64.exe?I21DBN=LINK\&P2 $1 \mathrm{DBN}=\mathrm{UJRN} \& Z 21 \mathrm{ID}=\& \mathrm{~S} 21 \mathrm{REF}=10 \& \mathrm{~S} 21 \mathrm{CNR}=2$ $0 \& S 21 \mathrm{STN}=1 \& \mathrm{~S} 21 \mathrm{FMT}=\mathrm{ASP}$ meta $\& \mathrm{C} 21 \mathrm{COM}=\mathrm{S}$ \&2_S21P03=FILA=\&2_S21STR=Vzhdtu_2016_3 11

10. S.E. Saukh, Visnik NAN Ukraine. No.4 (2018) URL:

ftp://ftp.nas.gov.ua/akademperiodyka/Downloads/Vi snyk_NANU/downloads/2018/PDF_Visn_42018/Visn_4-2018+11_Sauh.pdf

11. Y. Halynska, Problems and Perspectives in Management. Vol. 16, issue 1, pp. 1-11 (2018) URL:

https://businessperspectives .org/journals/problemsand-perspectives-in-management/issue-

276/strategic-view-on-the-rental-policy-in-the-fieldof-environmental-management

12. Yu.T. Matvieieva, T.V. Bondar, Iu.O. Myroshnychenko, Economic Annals-XXI. 7-8(1), pp. 40-44 (2015) URL: http://soskin.info/userfiles/file/2015/78_1/Bondar_Matvieieva_Myroshnychenko.pdf

13. Yu.V. Halynska, Scientific Bulletin of Kherson State University. Economic sciences. Issue. 23 (2017)

URL: http://www.ej.kherson.ua/journal/economic_23/econ omic 23_1.pdf

14. Yu.T. Matvieieva, T.V. Bondar, A.I. Kurasov, Economy and state.No. 3, pp. 124-131 (2019) URL: http://www.economy.in.ua/?op=1\&z=4290\&i=21

15. Yu. Halynska, V. Oliinyk, Journal of Advanced Research in Law and Economics. Vol. XI, Issue 2(48) (Spring 2020)

16. Y. Halynska, A. Telizhenko, Problems and Perspectives in Management: - LLC "Consulting Publishing Company "Business Perspectives". Vol. 14, Issue 4, pp. 181-185 (2016) https://doi.org/10.21511/ppm.14(4-1).2016.06 (DOI: 10.21511/ppm.14(4-1).2016.06)

17. Y. Halynska, Marketing and Management of Innovations. Issue 2, pp. 147-261 (2018) 